Article

\title{
Push and Pull Travel Motivation: Segmentation of the Greek Market for Social Media Marketing in Tourism
}

\author{
Christina Katsikari ${ }^{1}$, Leonidas Hatzithomas ${ }^{1, * \mathbb{D}}$, Thomas Fotiadis ${ }^{2}$ and Dimitrios Folinas ${ }^{3}$ \\ 1 Department of Business Administration, University of Macedonia, 54636 Thessaloniki, Greece; \\ christinakatsikari@gmail.com \\ 2 Department of Production Engineering and Management, Democritus University of Thrace, 67100 Xanthi, \\ Greece; tfotiadi@pme.duth.gr \\ 3 Department of Logistics, International Hellenic University, 60100 Katerini, Greece; folinasd@teicm.gr \\ * Correspondence: hatzithomas@uom.edu.gr
}

Received: 18 May 2020; Accepted: 6 June 2020; Published: 11 June 2020

\begin{abstract}
The intense competition in the tourism sector increasingly pushes tourism destination marketers to seek more effective promotional practices, so that they remain competitive and attract more visitors. The fast expansion of the Internet and social media provides the opportunity for destination marketers to approach potential tourists in a simple and cost-effective way. While managing the official pages of destinations on social media, the basic question that arises is the configuration of the content, and how attractive this content could be for potential tourists. The purpose of this study is to investigate what elements of a destination, when displayed on social media, could be attractive factors for tourists. Through the analysis of push and pull tourism motivation factors in particular, this study focuses on the segmentation of the Greek market for those traveling abroad and the emergence of the basic elements that could attract each segment through social media. The respondents have been classified into four segments, according to the motives that more greatly influence their desire to travel. This analysis also shows the important relationships between these segments and the pull motivation factors on social media. The study concludes with findings and suggestions that can contribute to the planning of an effective social media marketing plan.
\end{abstract}

Keywords: market segmentation; push motivation; pull motivation; tourism; social media; Greece

\section{Introduction}

Tourism is one of the biggest industries with a significant contribution to the global economy of more than 8.8 trillion dollars in 2018 [1]. The industry continues to grow almost every year. International tourist arrivals increased worldwide, from 809 million in 2005 to 1.4 billion in 2018 . This number is expected to exceed 1.8 billion by 2030 [2]. However, in recent years, due to the intense competition in every tourist service, it has been important for tourism service providers to find and keep visitors in their destinations [3,4]. Therefore, researchers and tourist destination promoters pay attention to methods and practices of attracting tourists to destinations and improving their destination marketing strategy.

According to Fodness and Murray [5], before choosing a destination tourists spend a lot of time searching for information, as tourism is a high-involvement service. Searching is defined as the need for tourists to consult many different sources before making their decision in order to make travel arrangements easier [5]. Information is often used to minimize the perceived risk and the uncertainty associated with destinations that travelers do not know [6]. The destination image 
influences the perceived quality, satisfaction, consumer behavior, and willingness of the consumer to choose [7]. For this reason, positive image destinations are more likely to be included and selected in the decision-making process $[7,8]$.

Usually, the choice among a set of alternative destinations is a complex process, influenced by many factors and external sources of information. In the past, tourists mainly relied on commercial sources to form an image for a destination before making their final decision [6]. Today, searching is based on completely different methods and sources. Due to the high level of perceived risk involved in traveling, tourists are driven to find more trustworthy sources, such as personal resources and word of mouth (WOM). Litvin et al. [9] define WOM as "the communication between the consumers about a product, service, or company, which is independent of commercial influence". It has been shown that positive WOM increases purchase intention by creating a valuable brand image and reducing the risk that consumers perceive in selecting products [10].

Today, the spread of the Internet and social media allows tourists to make most of the travel arrangements required before a trip. They can search for information about destinations, travel offers, transportation, and accommodation, even seeing photos and videos from these destinations. They can also compare prices and services. They can make their bookings and purchases of tourist products and services; finally, they can suggest a destination through eWOM (electronic word of mouth) [11]. By understanding the relationships between the characteristics of different social media platforms and destination selection, businesses and tourism promoters can improve their efforts and marketing strategies. For this to happen, it is necessary to examine the factors that influence the choice of a destination through social media. Of great interest is the role of social media in the image of a destination: how they are being used, by whom, what kind of content can be promoted through these platforms, and how they could influence consumer behavior in terms of tourism products and services [12].

This study is focused on examining the kinds of social media content that are more likely to be attractive for potential tourists, to influence their destination choice, based on their motivation to travel. Previous studies argue that motivation is what pushes people to travel and, at the same time, what attracts them to specific destinations $[13,14]$. Several studies have been conducted in the past to identify the push and pull factors that frame travelers' motivation, as well as to understand how these factors can be used to increase the effectiveness of marketing strategies $[13,15,16]$.

The present study elaborates on the methodology of Oh et al. [17], according to which tourists can be classified into different market segments based on their travel motivation. Segmentation helps to predict the items that attract people to choose a particular destination. The purpose of this research is to investigate whether the segmentation analysis based on push and pull factors could be applied in the social media context; that is, we examine the influence of tourists' motives to travel on their preferences for travel information on social media, in the pre-travel phase. The study addresses the following research questions. Is there a relationship between:

1. the push variable "knowledge/intellectual" and the pull variable "culture/history" (as presented on social media);

2. the push variable "sports" and the pull variable "activity/sports" (as presented on social media);

3. the push variable "novelty/adventure" and the pull variable "activity/sports" (as presented on social media);

4. the push variable "novelty/adventure" and the pull variable nature/outdoor (as presented on social media);

5. the push variable "escape/entertainment/prestige" and the pull variable "safety/luxury" (as presented on social media)?

The results of this study will highlight the relationships between different market segments and different kinds of social media content for tourist destinations and may contribute in several ways to the literature in terms of the use of social media in tourism marketing. (a) Our findings offer 
new insight into the use of social media as a business tool through which hospitality companies will engage, support, and connect travelers. According to Leung et al.'s recent review [18], the tourism business perspective of social media marketing is an under-researched area. (b) This study also gives hospitality businesses new ways to deliver value to customers, by involving them in value co-creation through the use of social media. (c) The role of social media has been neglected in the stream of research on push and pull travel motivation. Extending this stream of research, the present study sheds light on the interplay between tourists' motives to travel to a destination and social media travel content. (d) We also expand the literature on sustainable tourism by evaluating the importance of different travel motives on the travelers' preference for social media content that relates to the physical environment (i.e., natural and outdoor environments). Although prior studies [19] have underscored the role of social media in tourists' intention to visit a rural touristic destination (i.e., a typical example of sustainable tourism), they did not investigate the relationship between tourists' motives to travel and their attitudes toward the information about natural areas (i.e., wilderness and undisturbed nature, national parks, forests, rivers) that is shared on social media.

\section{Literature Review}

\subsection{Social Media and Consumer Behavior}

The way tourists seek information about destinations, plan their trips, make reservations, and share their travel experiences has completely changed with the contribution of the Internet $[20,21]$. In recent years, social media, blogs, and websites have increasingly replaced traditional sources, providing tourists with a large amount of information and allowing them to share experiences more interactively [22]. Especially with the development of social media platforms, users can now learn about others' experiences and publish content such as comments, text, photos, or videos [12,22]. They are also able to find information before their trip, to support their destination choice, the travel planning process, and decisions on accommodation, activities, restaurants, and attractions [21].

Travel experiences are intangible services, as they cannot be assessed before consumption. Thus, recommendations from other people have a great influence on potential tourists, often greater than the advice of official tourism websites [23]. Electronic word of mouth or-advice from friends on the Internet is often ranked as the most important source of travel information before purchasing a tourist service [21]. User comments and posts not only have the potential to increase or decrease the number of visitors but also to develop expectations for tourist destinations [24]. A study by Prebensen et al. [25] shows that in the process of consuming one tourist service, there are causal relationships between travel motivation, tourist satisfaction, and motivation to communicate with other tourists through the eWOM process. She suggests that destination marketing organizations (DMOs) and tourism businesses should encourage tourists to share and narrate their experiences through social media platforms.

Social media have fundamentally changed the way tourists seek, see, trust, and create their own content about tourism service providers [26]. Tourists are now able to create and share a huge amount of information and content that contributes to the positive or negative image of a tourist experience. This phenomenon is called user-generated content (UGC) [27]. Wang et al. [28] found that when tourists share travel experiences through social media, their friends can "see" and "live" their experiences without being physically with them.

Tourists' constant connectivity to social media, through smartphones, offers new opportunities for tourism providers to target markets in real time based on their locations [29]. During their travels, tourists tend to express their feelings on social media, to find tourism information about sights to see, events to attend, and destinations to travel to, as well as to co-create value and experience with tourism providers. They also post small emotional stories about their experiences (i.e., storytelling), share content on social media that indicates their satisfaction or disappointment with the destination experience (i.e., triggers), express their attitudes through their likes on tourism brands (i.e., amusement), 
and create active posts and comments about the destination (i.e., reaction) (i.e., the Storytelling, Triggers, Amusement and Reaction-STAR-model) [30]. Tourists who can be characterized as "daily life controllers" and "social media addicts" in particular tend to be frequently involved with their social media contacts and maintain a high level of social media presence when traveling [31].

Hence, today's travel companies adopt a social context mobile (SoCoMo) marketing approach by collecting and analyzing any information that can characterize the situation of a tourist; that is, external contextual information, such as location, season and time, political and social environment, emergencies, weather, and internal contextual information, such as likes, emotional status, goals, and topics of interest [32]. They invest in customer-dominant logic-based ecosystems that provide hyper-personalized and beyond-automated experiences, enhancing tourists' engagement with a tourism brand and improving quality of life for both tourists and residents in smart tourism destinations [33].

According to Kim and Tussyadiah [34], the tourist experience is not only based on the activities taking place at the destination, but also on whether tourists are dreaming about a future trip, planning and/or collecting information for it, or recalling previous travel experiences. This study clearly shows that travelers are not only passive consumers who can only accept information; they are also creators, editors, and distributors of information [12,35]. Travelers create their own destination material mainly through comments, photos, and videos. This type of non-promotional communication has a great influence on destinations' image, often greater than the communication of the DMOs. The Internet has changed consumers' behavior in the tourism industry, as well as the behavior of promoters of tourism destinations. Manap and Adzharudin [36] highlight the importance of the Internet in the development of a destination, arguing that social media is one of the major destination promotion tools.

\subsection{Social Media Content and Destination Marketing}

For online destination marketers, it is very important to understand the role of the type, quantity, and-mainly-all the creative elements that constitute the content displayed on social media. Mariani et al. [37] show that visual content, such as photos and videos, is the type of content that generates the most comments and user engagement. The significant relationship between visual content and user engagement confirms that tourists (or potential travelers) using social media platforms are attracted by images of the sights and destinations they are planning to visit. Previous studies also support the strong relationship between tourism and visual content generation [38]. During recent years, DMOs have fully recognized the need for displaying more visual content on their official social media pages [39].

A plethora of studies has investigated the role of visual content and its importance in consumer behavior [40]. Photographs are a means of "capturing" reality [41]. According to Albers and James [42], "photographs are the means that allow people to connect with visual images and make them their own". From a marketing perspective, photographs are the practice of selecting and modifying what will be communicated to the public and then changing and further editing what is finally published [43]. From the traveler's point of view, photographs are a popular way of communicating their personal travel experiences and the way the image of a destination is perceived [44].

According to Hall [43], photography has an important role in the tourism industry, as visual communication can trigger the imagination and can influence consumers without even seeming to do so. Albers and James [42] attempted to study the relationship between tourism, nationality, and photography. According to them, travel photos not only determine what tourists see and how they see it but also how they perceive what they see. They argue that there are two essential elements in a photo: its content and its composition. The content refers to all the elements that have been included in a photo. The way these elements are linked together and presented to the viewer is the composition of the photograph.

In the tourism industry, the purpose of visual content is to create a good perception of the tourist destination. User-generated images will be generated, discussed, and disseminated to social media 
through the "silent" word of mouth model. In other words, digital photography and video, as provided by social media, are symbols of the reality and experience of users as travelers [45].

Given the intangible features of traveling that tourists cannot experience beforehand, visual content is a key tool for tourism businesses. Thus, they publish visual content on various online platforms to promote destinations and provide tourists with a virtual experience of both the destination and the tourist service in total [46]. Visual features have an important role in the pre-traveling experience of tourists and therefore in decision making. Content such as videos and photos is a kind of authentic experience and provides visual insights into destinations and tourist services.

Analysis of the DMOs' posts on Facebook has also shown that evening posts lead to higher user engagement as the number of posts is smaller (and therefore a post is more visible), and users also spend more time on Facebook during this time of the day [37]. Previous research also shows that users' engagement is greater during the weekends. Besides, engagement seems to be maximized when the daily frequency of postings is low; that is, few quality posts lead to higher engagement. The length of a post can also have an impact on the engagement since posts of about 200 characters result in the highest user engagement.

Prior studies have also highlighted the importance of comments and online reviews of products and services. Given that the travel service is usually related to the experience, online reviews are a valuable source of information for travelers [47]. These reviews can positively or negatively affect the demand for a tourist service. According to Collie [48], 69\% of the plan that tourists make before a trip is determined by online reviews from previous visitors. Available online reviews are greater in number for hotels or restaurants, and fewer for sightseeing or activities at a destination. Although they are all tourism-related experiences, they could differentiate as services [47]. Specifically, the overall quality of hotels can usually be assessed and predicted by their stars, which are defined by a specific and objective framework. On the other hand, many of the basic elements of a destination do not have a similar rating system. A frustrating tourist attraction can cause more disappointment than a meal at a restaurant. Therefore, tourism marketers need to understand how online reviews can influence the choice of destination.

Apart from the type, timing, and length of the content posted on social media, the most significant aspect for marketing experts is considered to be the topic of the content, which means all the creative elements that either portray or describe a feature of a destination. Specifically, what exactly are these elements that seem to be more appealing to potential tourists, and could stimulate their interest while they are on social media looking for travel content, or doing something completely different? Every day, there are millions of destination-related social media posts coming from destination promoters and businesses, and even more from the travelers themselves who share their experiences online. Indeed, other visitors' posts often create a desire for other potential tourists to visit the same place. The content of these posts includes everything a visitor can experience in a destination, including landscapes, sights, activities, food or drink, local products, events, and so on. Anything that is part of the tourist experience can be shared on social media.

The elements of the content that could attract potential tourists depend on many factors. One of the most important variables explaining consumer behavior is motivation [49]. All individuals are different, and so are the factors that motivate them. Their personality, lifestyles, past experiences, demographics, and perceptions determine the factors that motivate them. In the field of destination social media marketing, content that motivates and influences potential tourists is a key issue.

\subsection{Push and Pull Travel Motivation}

Tourism motivation is only one variable that explains tourist behavior; however, it is considered one of the most important factors, because it constitutes the impulse and the force behind each kind of behavior [15]. Many researchers have explored travel motivation, approaching various areas such as sociology and psychology [15,50]. Maslow's motivational theory [51], modeled as a pyramid of 
hierarchical needs, was widely applied in the tourist literature in the early studies that examined tourism motives.

Many scientists tried to modify empirically Maslow's model. A generally accepted analysis of tourism motivation is based on push and pull factors $[13,14]$. This analysis argues that people travel or they need to travel because they are pushed by their internal forces. At the same time, they are attracted to the external characteristics of a destination when making their destination choice. Pull factors include tangible resources that determine the attractiveness of the destination, such as landscapes, beaches, and historical resources [16]. On the other hand, most of the push factors are intangible, or they express the internal desires of travelers; for example, the need for relaxation, adventure, prestige, and so on.

Crompton's [15] early study attempted to identify the motivation of leisure traveling that affects the choice of destination by defining a conceptual framework of push and pull factors. From his research nine motives arose. Seven of them were classified as socio-psychological motives or push motives: escape, exploration of self, relaxation, prestige, regression, enhancement of kinship relationships, and facilitation of social interaction. The other two, novelty and education, were characterized as cultural motives or pull motives. Crompton [15] concluded that destination has a significant impact on travel behavior and suggested that socio-psychological motivation needs to be taken into consideration for the development of tourism products and promotion strategies.

Many researchers attempted to develop alternative frameworks for push and pull motivation. According to Caber and Albayrak [52], previous studies on tourist motivation could be divided into three categories. The first group is mainly focused on personal motivations that lead people to specific behaviors [50], and also on how the demographic characteristics of a group are related to motivational differences [53]. For example, Yuan and McDonald [13], based on the concept of push and pull, were focused on motives for traveling abroad. Research data were collected from Japan, France, West Germany, and the United Kingdom. They determined five push factors (escape, originality, prestige, relationship enhancement, and relaxation/hobby), as well as seven pull factors (budget, culture/history, wildlife, ease of travel, cosmopolitan environment, and hunting). Originality was distinguished as the most important push factor for holidays abroad. In the second group, studies showed the relationships amongst motivation and other variables, such as customer satisfaction and behavioral intention $[54,55]$.

Studies in the third group examined how motivation could be used for market segmentation. Oh et al. [17] investigated the relationship between push and pull factors for those traveling abroad, using the method of canonical correlation analysis. In their survey, conducted in Australia, a sample of 1030 people were asked to evaluate 30 push and 52 pull tourism motivation factors on a Likert scale. Then, by grouping the above items, the most important stimulation variables (or factors) were formed. Six push variables were formed: knowledge/intellectual, sports, novelty/adventure, entertainment/prestige, kinship/social interaction, and escape/rest. From the pull items, five variables were formed: cultural/historical, safety/upscale, activity/sports, nature/outdoor, and inexpensive/budget. Oh et al. [17] showed that travelers could be classified into delineated variates based on the motives that push and attract them. Combining push and pull variables, four major variates emerge that determine the market segments, depending on each segment's interests, as follows: activity/sports seekers, safety/comfort seekers, culture/novelty, and luxury seekers. Tourists that classified in different segments appear to be more attracted by different pull factors. Thus, understanding the different needs that tourists have in each of the above segments is essential for the effectiveness of marketing strategies.

Moreover, Baloglu and Uysal [16] attempted to describe market segments as a function of the motivation factors for traveling abroad with a sample of 1212 respondents from Germany, by using canonical correlation analysis. Their research confirmed the importance of the relationship between push and pull factors; they found four different market segments, based again on the needs of each segment: sports/activity seekers, novelty seekers, urban-life seekers, and beaches/resort 
seekers. Significant relationships between push and pull elements arose again but there were some differences from Oh et al.'s [17] findings, demonstrating that different samples can yield different results. According to the conclusions of this survey, market segmentation helps tourism businesses and organizations to create more successful marketing strategies and promotional actions.

Several related studies have been conducted during recent years in the same field [56-58], for different tourism services [59] or groups with different characteristics. Pesonen [60] combined segmentation approaches, namely motivation and benefit segmentation, and the segment of online rural tourists in Finland. Using cluster analysis on tourists' motivations, four rural tourist segments were found: social travelers, wellbeing travelers, home region travelers and family travelers. Li et al. [61] surveyed Chinese outbound tourists; using canonical correlation analysis, they segmented them into three groups with an overlapping segment: entertainment/adventure seekers, life-seeking experience/culture explorers, and relaxation/knowledge seekers. The survey of Whyte [62] examined the onboard and onshore attributes of a cruise vacation and identified market segments, measuring the importance of the relationship of push and pull factors in the decision-making process of cruise travelers. The market segmentation of seniors was also an interesting application of push and pull motivation, as this is a heterogeneous group, with great purchasing power and lifestyle-oriented entertainment and enjoyment of leisure time. Understanding the importance of this group to the tourism industry, Alén et al. [63] found five market segments according to the behavioral variables analyzed.

\section{Research Hypotheses}

All the above studies on the analysis of push and pull factors refer to the tangible pull factors provided by a destination and could be perceived by a traveler during their visit to this destination. What has not yet been investigated is whether this analysis could be applied in the case where the pull factors are being displayed on social media and presented to potential tourists before their trip, something that we will examine in this study.

Based on a previous literature review on travel motivation factors and mostly on the research of Oh et al. [17] for those traveling abroad, the relationships we expect to emerge between push and pull elements displayed on social media are as follows (see also Figure 1):

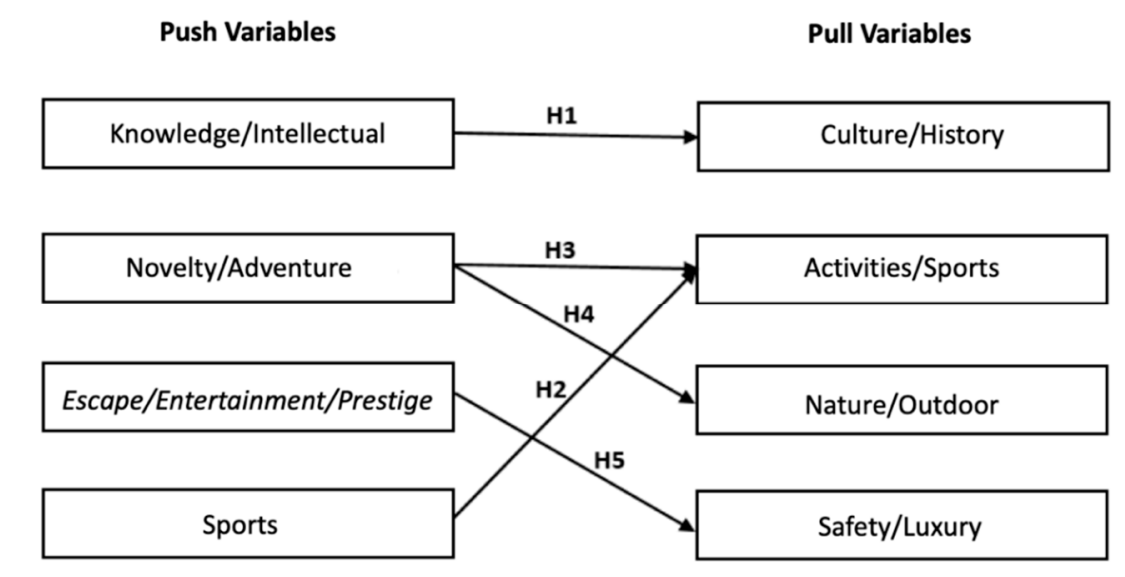

Figure 1. Research Hypotheses.

Hypothesis 1 (H1). There is a positive relationship between the push variable "knowledge/intellectual" and the pull variable "culture/history" (through social media).

Hypothesis 2 (H2). There is a positive relationship between the push variable "sports" and the pull variable "activity/sports" (as presented on social media). 
Hypothesis 3 (H3). There is a positive relationship between the push variable "novelty/adventure" and the pull variable "activity/sports" (as presented on social media).

Hypothesis 4 (H4). There is a positive relationship between the push variable "novelty/adventure" and the pull variable "nature/outdoor" (as presented on social media).

Hypothesis $\mathbf{5}$ (H5). There is a positive relationship between the push variable "escape/entertainment/prestige" and the pull variable "safety/luxury" (as presented on social media).

\section{Methodology}

\subsection{Research Methodology Overview}

In this paper, a quantitative analysis was applied to identify and present the relationships between Greek market segments and social media pull factors. Primary data were collected via questionnaires that were filled in by 221 people, from 6 to 26 June 2019. The statistical analysis of the responses includes both descriptive and inferential statistical analyses and was performed with the SPSS program (v.23). Greece was chosen as the context of the study because it is a country that depends heavily on tourism. Tourism accounts for $12.1 \%$ of GDP, and $20.8 \%$ of the total Greek economy, while it provides 846,200 jobs (21.7\% of total employment) [64]. There are about 8 million $(74.9 \%)$ active social media users in Greece [65], whereas more than one fourth (25.8\%) of Greeks use the Internet to buy tourism services [66]. A plethora of studies on tourism has been carried out in Greece [67-69], offering a stable basis for the analysis of push and pull tourism motivation factors in the social media context.

\subsection{Measures}

The questionnaire used in this research was created and distributed online to the participants. It was designed based on the study of Oh et al. [17], using 18 push and 18 pull items for those traveling abroad. The items for push travel motivation were evaluated on a Likert scale with values from 1 (not at all important) to 5 (very important) (Table 1).

Table 1. Tourism motivation push items.

\begin{tabular}{cll}
\hline Push Items & Mean & S.D. \\
\hline Escaping from the ordinary & 4.27 & 0.84 \\
Seeing as much as possible & 4.26 & 0.90 \\
Getting a change from a busy job & 4.10 & 0.98 \\
Seeing and experiencing a foreign destination & 4.05 & 0.90 \\
Entertainment and recreation & 3.99 & 0.93 \\
Learning new things, increasing knowledge & 3.97 & 0.94 \\
Experiencing new and different lifestyles & 3.73 & 1.00 \\
Being daring and adventuresome & 3.67 & 1.07 \\
Tasting different food/flavors & 3.54 & 1.14 \\
Traveling to historically important places & 3.43 & 1.08 \\
Finding thrills and excitement & 3.24 & 1.14 \\
Being free to act the way I feel & 3.21 & 1.32 \\
Narrative of travel experiences after the return & 3.07 & 1.31 \\
Indulging in luxury & 2.96 & 1.24 \\
Being physically active & 2.55 & 1.15 \\
Going to places friends haven't been & 2.14 & 1.25 \\
Watching sports games and activities & 1.94 & 1.16 \\
Participating in sports & 1.82 & 0.93 \\
\hline
\end{tabular}

The research participants were asked to evaluate how important each item is for them when they are thinking about taking a trip abroad. Regarding the pull items, they were asked to evaluate how important it is for them to see content about each item on social media when they search for destinations and leisure trips online (Table 2). 
Table 2. Tourism motivation pull items.

\begin{tabular}{cll}
\hline Pull Items & Mean & S.D. \\
\hline Outstanding scenery & 4.26 & 0.82 \\
Exotic atmosphere & 3.88 & 1.00 \\
Culture different from my own & 3.87 & 0.94 \\
Beaches for swimming and sunbathing & 3.85 & 1.06 \\
Traditional food/local cuisine & 3.74 & 1.08 \\
Local festivals and events & 3.70 & 1.03 \\
National parks, forests, rivers & 3.57 & 1.08 \\
Large and modern cities & 3.51 & 1.13 \\
Historical and archaeological sites & 3.47 & 1.12 \\
Wilderness and undisturbed nature & 3.21 & 1.18 \\
Amusement or theme parks & 3.19 & 1.07 \\
Museums and art galleries & 3.14 & 1.22 \\
High-quality restaurants & 3.02 & 1.17 \\
Nightlife and entertainment & 3.01 & 1.07 \\
Shopping malls & 2.95 & 1.26 \\
Luxury hotels & 2.84 & 1.22 \\
Water sports & 2.69 & 1.04 \\
Outdoor activities such as hiking/climbing & 2.42 & 1.07 \\
\hline
\end{tabular}

The sections of the questionnaire are as follows:

1. The first section is mainly about the respondents' preferences regarding the type of social media content that affects their opinion about destinations, and which social media platforms they consider most important in their search for travel and destinations.

2. The second contains the 18 push items that constitute people's motivation to take a leisure trip. The items were selected from Oh et al.'s [17] push factors: knowledge/mentality, escape/rest, fun/prestige, sports, and novelty/adventure.

3. The third section focuses on the 18 pull items displayed on social media, which attract tourists to choose a destination. The above items were selected from Oh et al.'s [17] pull factors: culture/history, nature/outdoors, sports/activities, and safety/luxury. The present study includes only the pull items that could be used on social media to promote a destination.

4. The fourth and final section of the questionnaire lists the demographic characteristics of the sample.

We carried out a pilot study before implementing the main study. A sample of ten experts was asked to read and complete the questionnaire and then comment on the overall picture, understanding, and process of completing the questionnaire. Corrections were then made where necessary to ensure that the questionnaire was clear and understandable.

\subsection{Sample}

The survey involved a total of 221 people and took place in the period from 6 to 26 June 2019. The demographic profile of the participants in this research is presented in detail in Table 3.

Table 3. Demographic profile of the sample $(\mathrm{N}=221)$.

\begin{tabular}{ccc}
\hline Demographics & Frequency Rate & $\%$ \\
\hline Sex & & \\
Male & 92 & 41.6 \\
Female & 129 & 58.4 \\
Age & & \\
$18-30$ & 166 & 75.1 \\
$31-40$ & 33 & 14.9 \\
$41-50$ & 12 & 5.4 \\
Over 51 & 10 & 4.5 \\
\hline
\end{tabular}


Table 3. Cont.

\begin{tabular}{ccc}
\hline Demographics & Frequency Rate & $\%$ \\
\hline Education & 19 & 8.6 \\
Secondary & 108 & 48.9 \\
Higher & 86 & 38.9 \\
Postgraduate & 8 & 3.6 \\
PhD & & \\
Professional Profile & 8 & 3.6 \\
Entrepreneur & 30 & 13.6 \\
Freelancer & 116 & 52.5 \\
Private sector employee & 15 & 6.8 \\
Public sector employee & 38 & 17.2 \\
Student & 1 & 0.5 \\
Retired & 13 & 5.9 \\
Unemployed & & \\
Number of Trips Per Year & 5 & 2.3 \\
Less than one & 46 & 20.8 \\
One & 71 & 32.1 \\
Two & 79 & 35.7 \\
Three to five & 20 & 9.0 \\
More than five & $\mathbf{2 2 1}$ & $\mathbf{1 0 0 . 0}$ \\
Total & &
\end{tabular}

From a total of 221 participants, 129 (58.4\%) identified themselves as female and $92(41.6 \%)$ as male. Most of the respondents were less than 40 years old. Overall, $75.1 \%$ of the sample represent the first age group (18-30) while only $14.9 \%$ of the sample are in the $31-40$ age group. The respondents were more likely to have higher or postgraduate education, with a percentage of $48.9 \%$ and $38.9 \%$, respectively. Finally, participants were more likely to take up to 2 trips per year (32.1\%), or 3-5 trips per year $(35.7 \%)$.

\section{Results and Discussion}

According to previous studies $[16,17]$, the push factors represent the segmentation of a market. Thus, the respondents were classified into four main segments according to their travel motives.

These segments are defined as follows:

(1) "Knowledge/intellectual": The participants in this segment tend to put priority on the enhancement of their knowledge during their vacations, and the experience of a new culture and traditions, also by visiting historical places.

(2) "Novelty/adventure": The main characteristic of the people in this segment is that they seek originality, new and fresh experiences, and to have an adventure during their vacation.

(3) "Escape/entertainment/prestige": This section includes those who seek comfort, luxury, relaxation, and fun during their vacation.

(4) "Sports": This segment concerns people who want to be physically active during their vacations and to attend or participate in sports activities.

We used Cronbach's alpha to assess the internal consistency reliability of these factors. Table 4 shows that the alpha coefficient is greater than 0.70 for all the push factors. Moreover, the results do not indicate that any of the items should be deleted to increase the value of Cronbach's alpha. Table 5 shows the pull travel motivation factors; namely, culture/history, activities/sports, nature/outdoor, and safety/luxury. The pull factors in this study represent the content being displayed on social media platforms, for the promotion of destinations. Cronbach's alpha is greater than 0.70 for all the pull factors, ensuring the internal consistency reliability of the variables, while it appears that none of these factors will be improved if any of the items are deleted. 
Table 4. Push travel motivation factors.

\begin{tabular}{cccc}
\hline Push Factors & $\begin{array}{c}\text { Cronbach's } \\
\text { Alpha }\end{array}$ & $\begin{array}{c}\text { Corrected Item } \\
\text { Knowledge/Intellectual }\end{array}$ & $\begin{array}{c}\text { Cronbach's Alpha if } \\
\text { Item Deleted }\end{array}$ \\
\hline $\begin{array}{c}\text { Experiencing new and different lifestyles } \\
\text { Seeing and experiencing a foreign destination }\end{array}$ & 0.74 & 0.52 & 0.69 \\
Learning new things, increasing knowledge & & 0.53 & 0.69 \\
Tasting different food/flavors & & 0.65 & 0.64 \\
Traveling to historically important places & 0.79 & 0.42 & 0.73 \\
Novelty/Adventure & & 0.44 & 0.72 \\
Being daring and adventuresome & & 0.55 & 0.76 \\
Escaping from the ordinary & & 0.55 & 0.77 \\
Finding thrills and excitement & 0.70 & 0.75 & 0.66 \\
Being free to act the way I feel & & 0.59 & 0.69 \\
Escape/Entertainment/Prestige & & 0.34 & 0.61 \\
Entertainment and recreation & & 0.57 & 0.66 \\
Seeing as much as possible & & 0.40 & 0.67 \\
Going to places friends haven't been & & 0.41 & 0.67 \\
Getting a change from a busy job & & 0.41 & 0.65 \\
Indulging in luxury & & 0.48 & 0.58 \\
Sports & & 0.75 & 0.74 \\
Participating in sports & & 0.58 & 0.78 \\
Being physically active & & 0.54 & \\
\hline Watching sports games and activities & & & \\
\hline
\end{tabular}

Table 5. Pull travel motivation factors.

\begin{tabular}{|c|c|c|c|}
\hline Pull Factors & Cronbach's Alpha & Corrected Item & $\begin{array}{c}\text { Cronbach's } \\
\text { Alpha if Item Deleted }\end{array}$ \\
\hline Culture/History & 0.78 & & \\
\hline Museums and art galleries & & 0.58 & 0.73 \\
\hline Local festivals and events & & 0.52 & 0.75 \\
\hline Historical and archaec & gical sites & 0.64 & 0.71 \\
\hline Culture different from my own & & 0.58 & 0.73 \\
\hline Traditional food/local cuisine & & 0.37 & 0.78 \\
\hline Outstanding scenery & & 0.50 & 0.75 \\
\hline Activities/Sports & 0.72 & & \\
\hline Water sports & & 0.37 & 0.70 \\
\hline Nightlife and entertainment & & 0.48 & 0.68 \\
\hline Beaches for swimming a & A sunbathing & 0.46 & 0.68 \\
\hline Outdoor activities such as & iking/climbing & 0.39 & 0.70 \\
\hline Amusement or theme parks & & 0.42 & 0.70 \\
\hline Exotic atmosphere & & 0.54 & 0.66 \\
\hline Large and modern cities & & 0.37 & 0.70 \\
\hline Nature/Outdoor & 0.74 & & \\
\hline \multicolumn{2}{|c|}{ Wilderness and undisturbed nature } & 0.59 & - \\
\hline National parks, forests, rivers & & 0.59 & - \\
\hline Safety/Luxury & 0.83 & & \\
\hline High-quality restaurants & & 0.66 & 0.79 \\
\hline Luxury hotels & & 0.75 & 0.70 \\
\hline Shopping malls & & 0.66 & 0.79 \\
\hline
\end{tabular}

Four two-step hierarchical regression analyses, with push motivation factors as independent variables, demographics (i.e., sex, age, and education) as covariates, and pull motivation factors as dependent variables, were conducted (Table 6). These models explain the relationships between tourists' push motivations to travel and the types of content they want to view on social media (i.e., pull factors).

The beta coefficients in Table 6 indicate the variability of each dependent variable (pull factors) that could be explained by each independent variable (push factors). The values of $R^{2}$, Adjusted $\mathrm{R}^{2}$, and $\mathrm{F}$ for each model also show what percentage of the variability of the dependent variable is explained by the independent variables, as well as the level of significance.

The four models are statistically significant at the 5\% level. The model for the pull variable "culture/history" interprets $44 \%\left(R^{2}=0.44\right)$ of its variability, $42 \%\left(R^{2}=0.42\right)$ for "activities/sports", $22 \%$ $\left(R^{2}=0.22\right)$ for "nature/outdoors" and $28 \%\left(R^{2}=0.28\right)$ for "safety/luxury". 
Table 6. The effect of push travel variables on pull travel variables displayed on social media.

\begin{tabular}{|c|c|c|c|c|c|c|c|c|}
\hline \multirow[t]{2}{*}{ Pull Variables } & \multicolumn{2}{|c|}{ Culture/History } & \multicolumn{2}{|c|}{ Activities/Sports } & \multicolumn{2}{|c|}{ Nature/Outdoor } & \multicolumn{2}{|c|}{ Safety/Luxury } \\
\hline & M1 & M2 & M1 & M2 & M1 & M2 & M1 & M2 \\
\hline \multicolumn{9}{|l|}{ Control Variables } \\
\hline Sex & 0.14 * & 0.04 & 0.01 & 0.02 & -0.08 & -0.09 & 0.07 & -0.01 \\
\hline Age & -0.04 & 0.05 & $-0.28^{* * *}$ & $-0.16^{* *}$ & -0.12 & -0.03 & 0.04 & 0.06 \\
\hline Education & 0.12 & $0.14^{* *}$ & 0 & 0.07 & -0.02 & 0.03 & 0.07 & 0.1 \\
\hline \multicolumn{9}{|l|}{ Push Variables } \\
\hline Knowledge/Intellects & & $0.6^{* * *}$ & & $0.16^{* *}$ & & $0.24^{* * *}$ & & 0.03 \\
\hline Novelty/Adventure & & 0.01 & & 0.18 * & & 0.15 & & -0.06 \\
\hline Escape/Entertainmen & /Prestige & 0.12 & & $0.17^{*}$ & & 0.07 & & $0.59^{* * *}$ \\
\hline Sports & & -0.1 & & $0.35^{* * *}$ & & $0.22 * * *$ & & -0.05 \\
\hline$R^{2}$ & 0.04 & 0.46 & 0.08 & 0.44 & 0.02 & 0.24 & 0.01 & 0.31 \\
\hline Adjusted $\mathrm{R}^{2}$ & 0.02 & 0.44 & 0.06 & 0.42 & 0.01 & 0.22 & 0 & 0.28 \\
\hline $\mathrm{F}$ & 2.84 * & $25.39^{* * *}$ & $5.94^{* * *}$ & $24.01^{* * *}$ & 1.48 & $9.80^{* * *}$ & 0.7 & $13.40^{* * *}$ \\
\hline
\end{tabular}

The two-step regression analysis with the pull factor "culture/history" as the dependent variable reveals two statistically significant relationships. It appears that tourists' education level influences the pull factor "culture/history". The higher their level of education, the more likely they are to be attracted and influenced by social media content related to historical or cultural topics (Beta $=0.14$, $p<0.01)$. There is also a positive relationship between the push factor "knowledge/intellectual" and pull factor "culture/history" (Beta $=0.6, p<0.001$ ). Thus, H1 is supported. This is in line with previous studies [16,17], showing that tourists who look for opportunities to increase their knowledge and satisfy their intellectual needs want to experience a culture that is different from their own and visit historic old cities. The present study extends previous research by revealing that this exact market segment searches for cultural and historical content on social media before traveling internationally.

The two-step regression analysis with the pull variable "activities/sports" as the dependent variable uncovers a number of relationships. Interestingly, but not surprisingly, the older a person is, the less likely they are to be influenced by social media content related to sports activities (Beta $=0.16$, $p<0.001$ ). The findings also indicate that the push variable "sports" has a positive relationship with the pull variable "activities/sports" (Beta $=0.35, p<0.001$ ). This supports H2. Prior studies also support this relationship [16], highlighting that tourists who want to stay fit during their vacations are attracted by destinations that offer sports activities. The push variable "novelty/adventure" also positively influences the pull variable "activities/sports" (Beta $=0.18, p<0.05$ ). Hence, H3 is supported. In their study, Oh et al. [17] found that the novelty seekers market segment has a high overlap with the sports seekers segment; they look for adventure and intense thrills during their holidays, in order to escape from their everyday life. In the same vein, the present study demonstrates that both market segments are being attracted by information about sports activities in social media. Two more push variables, "knowledge/intellectual" (Beta $=0.16, p<0.001)$ and "escape/entertainment/prestige" (Beta $=0.17$, $p<0.05)$, have a positive effect on the pull factor "activities/sports". It appears that social media content which focuses on activities and sports could attract tourists from all segments of the market, a result that is inconsistent with prior findings from the tourism literature [17]. This may be attributed to the growing interest in exercise and sports, as well as the trend of sharing fitness data through social media [70]. Nowadays, tourists are intensely interested in fitness advice and techniques, searching for fitness centers, a fundamental component of the contemporary hospitality experience [71]. Hence, it is reasonable for them to be attracted by social media content for sports activities.

The two-step regression analysis with the pull variable "nature/outdoor" as the dependent variable shows that, contrary to $\mathrm{H} 4$, the relationship between the push factor "novelty/adventure" and the pull factor "nature/outdoor" is not statistically significant (Beta $=0.15, p>0.05$ ). Traditionally, Greeks are used to traveling domestically rather than abroad [72]. Most tourists in Greece are interested in relaxing and sunbathing on a beach under the sun, visiting archaeological sites, studying the history of the Ancient Greek civilization, meeting local communities, and eating traditional food [73]. Few could be 
characterized as "explorers" with an urge to experience outdoor adventures in natural areas abroad. This could explain why H4 is not supported. Furthermore, it appears that both the push variables "knowledge/intellectual" (Beta $=0.24, p<0.001$ ) and "sports" (Beta $=0.22, p<0.001$ ) have a positive relationship with the pull variable "nature/outdoor". It seems that especially Greek tourists who want to widen their knowledge and cover their intellectual needs seek social media content about natural outdoor areas. According to Baloglu and Uysal [16], even though the push variable "sports" and the pull variable "nature/outdoor" do not represent the same market segment, they have a close relationship. The "instagrammability" of a physical location is considered the most important factor for millennials in choosing a holiday destination. This may lead many young Greek tourists who try to stay fit on their holidays to prefer natural areas that offer opportunities for both hiking/jogging and photo-shooting.

The last two-step regression analysis with the pull variable "safety/luxury" as the dependent variable found a statistically significant relationship only between the push variable "escape/entertainment/prestige" and the pull variable "safety/luxury" (Beta $=0.59, p<0.001$ ). Thus, H5 is supported. This result is in line with Oh et al.'s [17] study, which found that luxurious hotels and destinations are more appealing to tourists who seek entertainment, relaxation, and prestige.

\section{Conclusions}

This study extends prior research by examining whether push motivation factors can predict the type of content that different market segments prefer on social media (i.e., pull factors). The findings of the present study indicate that most of the relationships between push and pull factors supported by the previous literature are also verified for social media tourism pull factors. Only one of the research hypotheses was rejected, whereas some new relationships emerged.

In particular, for the pull variable "culture/history", there is a positive and statistically significant relationship with the push variable "knowledge/intellectuality", as well as with the education control variable. This means that social media content that focuses on local events, culture, traditional elements, and historical sites is more likely to attract consumers belonging to the "knowledge/intellectual" segment and those who have high educational background.

The pull variable "activities/sports" has a statistically significant positive relationship with all four segments; that is, with all the push variables. Hence, social media content that emphasizes beaches, opportunities for sports or outdoor activities, and opportunities for entertainment and fun is more likely to attract tourists from all the four segments, but at a different level of intensity. As hypothesized, the push variable "sports" has the strongest relationship with the pull variable "activities/sports", a result consistent with previous literature [16,17]. In a similar way, there is a positive relationship between the push motivation variable "novelty/adventure" and the pull variable "activities/sports". Furthermore, two new relationships emerged in our study, among the push variables "knowledge/intellectual", "escape/entertainment/prestige" and "activities/sports". These findings reveal that social media can attract all four Greek market segments by offering tourists to participate in outdoor activities, such as hiking/climbing and water sports, as well as in nightlife and entertainment activities.

For the pull variable "nature/outdoor", two positive and statistically significant relationships with the push variables "knowledge/intellectuality" and "sports" were discovered: social media content that emphasizes wildlife, parks, and woodland is more likely to attract tourists belonging to the two aforementioned segments. Interestingly, these findings are not supported by the literature in which tourists who wish to experience adventures appear to be attracted by wilderness, undisturbed nature, forests, and rivers.

Finally, the pull variable "security/luxury" has a positive and statistically significant relationship only with the push variable "escape/entertainment/prestige"; social media content that illustrates luxury hotels, restaurants, and malls is more likely to attract tourists who are motivated by safety and luxury. The relationship between the two variables is in line with the findings of previous research. 


\section{Managerial Implications}

This study provides important policy and managerial implications to social media managers of tourist destinations and hospitality businesses. It offers valuable guidelines for a successful social media marketing strategy that will address the needs and preferences of specific target groups. In the present study, the Greek market was segmented into four different groups: "knowledge/intellectual", "novelty/adventure", "escape/entrainment/prestige" and "sports".

Specifically, participants in the "knowledge/intellectual" segment seem to regard social media content related to a destination's culture and history as more attractive. Thus, a social media strategy targeting this segment should include elements such as historical sites, local events, traditional food, and beautiful scenery. They are also attracted, to a lesser extent, by content about nature, outdoor activities, and sports. Therefore, elements related to undisturbed nature, parks, beaches, water sports, theme parks, or any kind of sports could also be used in social media campaigns for this segment.

The "novelty/adventure" seekers segment includes people who seek originality, new experiences, and adventure from their vacation. For them, social media content related to outdoor activities and sports seems to be the most attractive. Tourists in the "escape/entertainment/prestige" segment perceive social media content that is related to safety and luxury as the most attractive, such as luxury hotels, restaurants, and malls. To a lesser extent, this segment is influenced by outdoor activities and sports content. The "sports" lovers segment also want to participate in sports and to be physically active during vacations. An effective social media strategy for them should focus not only on outdoor activities and sports but also on the destination's natural elements.

The present study also shows that Greek tourists, regardless of their push motivation for tourism, place significantly greater importance on social media content about destinations that offer entertainment, fun and sports activities: they are attracted by social media content which emphasizes water sports, outdoor activities such as hiking/climbing, beaches for swimming and sunbathing, amusement or theme parks, exotic atmosphere, large and modern cities, nightlife and entertainment. Hence, tourism marketing managers should consider the content about activities and sports as an integral part of their tourism organizations' social media page.

Furthermore, when a tourism marketing manager intends to promote undisturbed natural destinations or national parks, forests, and rivers to Greek tourists, "knowledge/intellectual" and "sports" seekers are the two most appropriate target customer segments for them. These two Greek market segments appear to be the most susceptible to social media content focusing on the different types of sustainable tourism. Their lifestyle and perceptions of health, wellness, and fitness seem to match social media pages which illustrate physical areas and outdoor activities.

In general, a successful matching of push and pull motives is essential for an online marketing strategy in destination areas to effectively design promotional campaigns. These guidelines could help the destinations' social media managers who target Greek tourists so that they can present the most attractive aspects of a destination and positively influence tourists' behavior and their decision making.

\section{Limitations and Future Research}

The present research has been conducted under standard constraints, which are important to be mentioned and should be taken into consideration. The first limitation is related to the sample of the survey, as our sample is more concentrated around the young age group (18-30). As already mentioned, this age group represents the majority of social media users, but a different distribution of the sample may give different results. The research was also conducted for the Greek market, so the sample includes tourists who live in Greece. Different populations could be segmented in a different way, formatting dissimilar market segments or push factors.

A second limitation that should be mentioned at this point is the selection of the pull items displayed on social media. The selection of these elements was based on previous studies in which they represented tangible elements that could be found in a destination. In our case, these elements represent content on social media, which is displayed in order to promote a destination. It would be 
quite interesting for future studies to also include a qualitative research method focused on social media content for destinations, in order to define more pull items that could also form more or different pull factors.

Moreover, the use of social media big data in the investigation of relationships between market segments and social media is a very motivating research area. Even if big data generated across social media sites has created numerous opportunities for bringing more insights to decision makers, only a few studies on big data analytics have demonstrated support for strategic decision making [74,75]. It will be of great interest, for example, to examine digital tourism experiences, through several longitudinal case studies of various destinations in Greece [76].

Another interesting research area will be the examination of the effect of social media on the attractions of natural areas. According to Luque-Martínez, Faraoni and Doña-Toledo [77], natural areas are a tourism asset of immense importance. Nature tourism is a market niche with very specific characteristics, which is very common in Greece. In their study [77], behavioral patterns on Twitter and Facebook were addressed to identify profiles. The authors proved that this information was useful for benchmarking to compare the profiles or clusters according to their social network activity. A similar study carried out by Pino, Peluso and Met [78] examined a sample of tweets posted on the official Twitter pages of the same region's main tourism promotion agency. The results identify features that may increase the effectiveness of social media managers' promotional efforts and highlight differences across the two platforms. Joo, Seok and Nam [19] investigate how tourists' use of social media can affect their behavior, especially in sustainable tourism. They concluded that, "If marketers were to focus more on encouraging the sharing of tourism experiences, this could aid sustainable tourism growth" [19]. Thus, it would be interesting for future research to investigate the different segmentation procedures that successfully work in different social media promoting natural areas.

Author Contributions: Conceptualization, C.K.; Methodology, L.H.; Project administration, C.K.; Supervision, L.H.; Visualization, T.F.; Writing-original draft, C.K.; Writing—review \& editing, L.H. and D.F. All authors have read and agreed to the published version of the manuscript.

Funding: This research received no external funding.

Conflicts of Interest: The authors declare no conflict of interest.

\section{References}

1. Statista, Direct and Total Contribution of Travel and Tourism to the Global Economy from 2006 to 2018. Available online: https:/www.statista.com/statistics/233223/travel-and-tourism--total-economiccontribution-worldwide/ (accessed on 30 April 2020).

2. Statista, Number of International Tourist Arrivals Worldwide from 1996 to 2018. Available online: https://www.statista.com/statistics/209334/total-number-of-international-tourist-arrivals/ (accessed on 30 April 2020).

3. Horng, J.S.; Liu, C.H.; Chou, H.Y.; Tsai, C.Y. Understanding the impact of culinary brand equity and destination familiarity on travel intentions. Tour. Manag. 2012, 33, 815-824.

4. Ho, C.I.; Lee, Y.L. The Development of an e-travel service quality scale. Tour. Manag. 2007, 28, 1434-1449.

5. Fodness, D.; Murray, B. Tourist information Search. Ann. Tour. Res. 1997, 24, 503-523.

6. Beerli, A.; Martin, J.D. Factors Influencing destination image. Ann. Tour. Res. 2004, 31, 657-681.

7. Bigne, J.E.; Sanchez, M.I.; Sanchez, J. Tourism image, evaluation variables and after purchase behaviour: Inter-relationship. Tour. Manag. 2001, 22, 607-616.

8. Baloglu, S.; McCleary, K.W. A model of destination image formation. Ann. Tour. Res. 1999, 26, 868-897.

9. Litvin, S.W.; Goldsmith, R.E.; Pan, B. Electronic word-of-mouth in hospitality and tourism management. Tour. Manag. 2008, 29, 458-468.

10. Jeong, E.; Jang, S.S. Restaurant experiences triggering positive electronic word-of-mouth (eWOM) motivations. Int. J. Hosp. Manag. 2011, 30, 356-366.

11. Sotiriadis, M.D.; Van Zyl, C. Electronic word-of-mouth and online reviews in tourism services: The use of Twitter by tourists. Electron. Commer. R. 2013, 13, 103-124. 
12. Boyd, D.M.; Ellison, N.B. Social Network sites: Definition, History, and scholarship. J. Comput.-Mediat. Commun. 2007, 13, 210-230.

13. Yuan, S.; McDonald, C. Motivational determinants of international pleasure time. J. Travel Res. 1990, 24, $42-44$.

14. Uysal, M.; Hagan, L.A.R. Motivation of pleasure travel and tourism. Enc. Hosp. Tour. 1993, 21, $798-810$.

15. Crompton, J. Motivations of pleasure vacations. Ann. Tour. Res. 1979, 6, 408-424.

16. Baloglu, S.; Uysal, M. Market segments of Push and pull motivations: A canonical correlation approach. Int. J. Contemp. Hosp. Manag. 1996, 8, 32-38.

17. Oh, H.M.; Uysal, M.; Weaver P., A. Product bundles and market segments based on travel motivations: A canonical correlation approach. Int. J. Hosp. Manag. 1995, 14, 123-137.

18. Leung, X.Y.; Sun, J.; Bai, B. Thematic framework of social media research: State of the art. Tour. Rev. 2019, 74, 517-531.

19. Joo, Y.; Seok, H.; Nam, Y. The Moderating Effect of Social Media Use on Sustainable Rural Tourism: A Theory of Planned Behavior Model. Sustainability 2020, 12, 4095.

20. Buhalis, D.; Law, R. Progress in information technology and tourism management: 20 years on and 10 years after the Internet-The state of eTourism research. Tour. Manag. 2008, 29, 609-623.

21. Xiang, Z.; Gretzel, U. Role of social media in online travel information search. Tour. Manag. 2010, 31, $179-188$.

22. Chung, N.; Koo, C. The use of social media in travel information search. Telemat. Inform. 2015, 32, $215-229$.

23. Buhalis, D. Strategic use of information technologies in the tourism industry. Tour. Manag. 1998, 19, 409-421.

24. De Bruyn, A.; Lilien, G.L. A multi-stage model of word-of-mouth influence through viral marketing. Int. J. Res. Mark. 2008, 25, 151-163.

25. Prebensen, N.; Skallerud, K.; Chen, J.S. Tourist motivation with sun and sand destinations: Satisfaction and the wom-effect. J. Travel. Tour. Mark. 2010, 27, 858-873.

26. Sigala, M.; Christou, E.; Gretzel, U. Social Media in Travel, Tourism and Hospitality: Theory, Practice and Cases, 1st ed.; Ashgate Publishing Ltd.: Surrey, UK, 2012.

27. O'Connor, P. User-generated content and travel: A case study on Tripadvisor.com. In Information and Communication Technologies in Tourism; O'Connor, P., Höpken, W., Gretzel, U., Eds.; Springer: Vienna, Austria, 2008; pp. 47-58.

28. Wang, D.; Park, S.; Fesenmaier, D.R. The role of smartphones in mediating the touristic experience. J. Travel Res. 2012, 51, 371-387.

29. Buhalis, D.; Sinarta, Y. Real-time co-creation and nowness service: Lessons from tourism and hospitality. J. Travel Tour. Mark. 2019, 36, 563-582.

30. Tiago, F.; Couto, J.; Faria, S.; Borges-Tiago, T. Cruise tourism: Social media content and network structures. Tour. Rev. 2018, 73, 433-447.

31. Fan, D.X.; Buhalis, D.; Lin, B. A tourist typology of online and face-to-face social contact: Destination immersion and tourism encapsulation/decapsulation. Ann. Tour. Res. 2019, 78, 102757.

32. Buhalis, D.; Foerste, M. SoCoMo marketing for travel and tourism: Empowering co-creation of value. J. Dest. Mark. Manag. 2015, 4, 151-161.

33. Buhalis, D.; Harwood, T.; Bogicevic, V.; Viglia, G.; Beldona, S.; Hofacker, C. Technological disruptions in Services: Lessons from Tourism and Hospitality. J. Serv. Manag. 2019, 30, 484-506.

34. Kim, J.; Tussyadiah, I.P. Social networking and social support in tourism experience: The moderating role of online self-presentation strategies. J. Travel. Tour. Mark. 2013, 30, 78-92.

35. Yoo, K.H.; Gretzel, U. Influence of personality on travel-related consumer-generated media creation. Comput. Hum. Behav. 2011, 27, 609-621.

36. Manap, K.A.; Adzharudin, N.A. The role of user generated content (UGC) in social media for tourism sector. In Proceedings of the 2013 WEI International Academic Conference Proceedings, Istanbul, Turkey, 16-19 June 2013; pp. 52-58.

37. Mariani, M.M.; Di Felice, M.; Mura, M. Facebook as a destination marketing tool: Evidence from Italian regional Destination Management Organizations. Tour. Manag. 2016, 54, 321-343.

38. Beeton, S. Rural tourism in Australia-has the gaze altered? Tracking rural images through film and tourism promotion. Int. J. Tour. Res. 2004, 6, 125-135.

39. Munar, A.M.; Jacobsen, J.K.S. Motivations for sharing tourism experiences through social media. Tour. Manag. 2014, 43, 46-54. 
40. Hatzithomas, L.; Fotiadis, T.A.; Coudounaris, D.N. Standardization, adaptation, and personalization of international corporate social media communications. Psychol. Mark. 2016, 33, 1098-1105.

41. Stepchenkova, S.; Zhan, F. Visual destination images of Peru: Comparative content analysis of DMO and user-generated photography. Tour. Manag. 2013, 36, 590-601.

42. Albers, P.C.; James, W.R. Travel photography: A methodological approach. Ann. Tour. Res. 1988, 15, $134-158$.

43. Hall, S. The rediscovery of 'ideology': Return of the repressed in media studies. In Culture, Society and the Media; Gurevitch, M., Bennett, T., Gurran, J., Woollacott, J., Eds.; Routledge: New York, NY, USA, 2005; pp. 61-95.

44. Schmallegger, D.; Carson, D.; Jacobsen, D. The use of photographs on consumer generated content websites: Practical implications for destination image analysis. In Tourism Informatics: Visual Travel Recommender Systems, Social Communities, and User Interface Design, 1st ed.; Sharda, N., Ed.; IGI Global: Hershey, PA, USA, 2010; pp. 243-260.

45. Fatanti, M.N.; Suyadnya, I.W. Beyond User Gaze: How Instagram Creates Tourism Destination Brand? Procedia Soc. Behav. Sci. 2015, 211, 1089-1095.

46. Tussyadiah, I.P.; Fesenmaier, D.R. Mediating tourist experiences: Access to places via shared videos. Ann. Tour. Res. 2009, 36, 24-40.

47. Fang, B.; Ye, Q.; Kucukusta, D.; Law, R. Analysis of the perceived value of online tourism reviews: Influence of readability and reviewer characteristics. Tour. Manag. 2016, 52, 498-506.

48. Collie, M. Internet Leads Travel. Geton.com. Available online: http://www.geton.com/blog/geton/internetleads-travel (accessed on 30 April 2020).

49. Hudson, S. Tourism and Hospitality Marketing: A Global Perspective; Sage: London, UK, 2008.

50. Dann, G. Anomie, ego-Enhancement and tourism. Ann. Tour. Res. 1977, 4, 184-194.

51. Maslow, A.H. Motivation and Personality, 2nd ed.; Harper \& Row: New York, NY, USA, 1970.

52. Caber, M.; Albayrak, T. Push or pull? Identifying rock climbing tourists' motivations. Tour. Manag. 2016, 55, 74-84.

53. Kim, S.S.; Lee, C.K.; Klenosky, D.B. The influence of push and pull factors at Korean national parks. Tour. Manag. 2003, 24, 169-180.

54. Huang, Y.; Luo, S.; Ding, P.; Scott, N. Impressions of Liusanjie: A study of motivation, theatrical performance evaluation, and satisfaction. Curr. Issues Tour. 2014, 17, 280-296.

55. Yoon, Y.; Uysal, M. An examination of the effects of motivation and satisfaction on destination loyalty: A structural model. Tour. Manag. 2005, 26, 45-56.

56. Devesa, M.; Laguna, M.; Palacios, A. The role of motivation in visitor satisfaction: Empirical evidence in rural tourism. Tour. Manag. 2010, 31, 547-552.

57. Kim, K.; Noh, J.; Jogaratnam, G. Multi-destination segmentation based on push and pull motives: Pleasure trips of students at a US university. J. Travel. Tour. Mark. 2007, 21, 19-32.

58. Sung, Y.K.; Chang, K.C.; Sung, Y.F. Market segmentation of international tourists based on motivation to travel: A case study of Taiwan. Asia Pac. J. Tour. Res. 2016, 21, 862-882.

59. Bruwer, J.; Prayag, G.; Disegna, M. Why wine tourists visit cellar doors: Segmenting motivation and destination image. Int. J. Tour. Res. 2018, 20, 355-366.

60. Pesonen, J.A. Segmentation of rural tourists: Combining push and pull motivations. Tour. Hosp. Manag. 2012, 18, 69-82.

61. Li, X.R.; Meng, F.; Uysal, M.; Mihalik, B. Understanding China's long-haul outbound travel market: An overlapped segmentation approach. J. Bus. Res. 2013, 66, 786-793.

62. Whyte, L.J. Understanding the relationship between push and pull motivational factors in cruise tourism: A canonical correlation analysis. Int. J. Tour. Res. 2017, 19, 557-568.

63. Alén, E.; Losada, N.; de Carlos, P. Profiling the segments of senior tourists throughout motivation and travel characteristics. Curr. Issues Tour. 2017, 20, 1454-1469.

64. World Travel and Tourism Council, Greece 2020 Annual Research: Key Highlights. Available online: https://wttc.org/Research/Economic-Impact/moduleId/704/itemId/119/controller/DownloadRequest/action/ QuickDownload (accessed on 27 May 2020).

65. Hellenic Statistical Authority, Research on the Use of Information and Communication Technologies by Households and Individuals in 2019. Available online: https://www.statistics.gr/el/infographic-informationtechnologies-2019 (accessed on 27 May 2020). 
66. Hellenic Statistical Authority, Use of Electronic Commerce and Security on the Internet 2019. Available online: https://www.statistics.gr/el/infographic-ecommerce-2019 (accessed on 27 May 2020).

67. Buhalis, D. Tourism in Greece: Strategic analysis and challenges. Curr. Issues Tour. 2001, 4, 440-480.

68. Eeckels, B.; Filis, G.; Leon, C. Tourism income and economic growth in Greece: Empirical evidence from their cyclical components. Tour. Econ. 2012, 18, 817-834.

69. Chatzigeorgiou, C. Modelling the impact of social media influencers on behavioural intentions of millennials: The case of tourism in rural areas in Greece. J. Tour. Herit. Serv. Mark. 2017, 3, 25-29.

70. Gui, X.; Chen, Y.; Caldeira, C.; Xiao, D.; Chen, Y. When fitness meets social networks: Investigating fitness tracking and social practices on werun. In Proceedings of the 2017 Proceedings of the 2017 CHI Conference on Human Factors in Computing Systems, Denver, CO, USA, 6-11 May 2017; pp. 1647-1659.

71. Zopiatis, A.; Theocharous, A.L.; Constanti, P.; Tjiapouras, L. Quality, satisfaction and customers' future intention: The case of hotels' fitness centers in Cyprus. J. Qual. Assur. Hosp. Tour. 2017, 18, 1-24.

72. Tsartas, P.; Manologlou, E.; Markou, A. Domestic tourism in Greece and special interest destinations: The role of alternative forms of tourism. Anatolia 2001, 12, 35-42.

73. Yfantidou, G.; Costa, G.; Michalopoulos, M. Tourist roles, gender and age in Greece: A study of tourists in Greece. Int. J. Sport Manag. Recreat. Tour. 2008, 1, 14-30.

74. Miah, S.J.; Vu, H.Q.; Gammack, J.; McGrath, M. A big data analytics method for tourist behaviour analysis. Inform. Manag. 2017, 54, 771-785.

75. Filieri, R.; Alguezaui, S.; McLeay, F. Why do travelers trust TripAdvisor? Antecedents of trust towards consumer-generated media and its influence on recommendation adoption and word of mouth. Tour. Manag. 2015, 51, 174-185.

76. Del Vecchio, P.; Mele, G.; Ndou, V.; Secundo, G. Open innovation and social big data for sustainability: Evidence from the tourism industry. Sustainability 2018, 10, 3215.

77. Luque-Martínez, T.; Faraoni, N.; Doña-Toledo, L. Auditing the Marketing and Social Media Communication of Natural Protected Areas. How Marketing Can Contribute to the Sustainability of Tourism. Sustainability 2019, 11, 4014.

78. Pino, G.; Peluso, A.M.; Del Vecchio, P.; Ndou, V.; Passiante, G.; Guido, G. A methodological framework to assess social media strategies of event and destination management organizations. J. Hosp. Market. Manag. 2019, 28, 189-216.

(C) 2020 by the authors. Licensee MDPI, Basel, Switzerland. This article is an open access article distributed under the terms and conditions of the Creative Commons Attribution (CC BY) license (http://creativecommons.org/licenses/by/4.0/). 